\section{Case Reports in Gastroenterology}

Case Rep Gastroenterol 2016;10:617-622

DOI: $10.1159 / 000450679$

Publisned online: October 28, 2016
(C) 2016 The Author(s)

Published by S. Karger AG, Basel www.karger.com/crg

This article is licensed under the Creative Commons Attribution-NonCommercial 4.0 International License (CC BY-NC) (http://www.karger.com/Services/OpenAccessLicense). Usage and distribution for commercial purposes requires written permission.

\title{
Use of Direct-Acting Antivirals for the Treatment of Hepatitis C Virus-Associated Oral Lichen Planus: A Case Report
}

\author{
Kenji Misaka ${ }^{a}$ Takashi Kishimoto $^{b} \quad$ Yuji Kawahigashic ${ }^{c}$ Michio Sata $^{d, e}$ \\ Yumiko Nagaoc, e \\ ${ }^{a}$ Misaka Dental Clinic, Fukuoka, Japan; ${ }^{b}$ Kishimoto Dental Clinic, Fukuoka, Japan; \\ 'Department of Organ System Interactions and Information, Saga Medical School, \\ Saga, Japan; ${ }^{d}$ Nishinihon Hospital, Kumamoto, Japan; ${ }^{e}$ Research Center for Innovative \\ Cancer Therapy, Kurume University School of Medicine, Fukuoka, Japan
}

\section{Keywords}

Oral lichen planus · Extrahepatic manifestations · Hepatitis C virus · Interferon · Direct-acting antivirals
Abstract

Hepatitis $\mathrm{C}$ virus (HCV) is frequently associated with various extrahepatic manifestations such as autoimmune features and immune complex deposit diseases. Oral lichen planus (OLP) is one of the representative extrahepatic manifestations of HCV infection. Direct-acting antivirals (DAA) are highly effective and safe for the eradication of HCV. However, there is a lack of information regarding the association between HCV-associated OLP and interferon (IFN)free DAA therapy. Herein, we present the case of a 60 -year-old female who was diagnosed with OLP during routine periodontal treatment by a dentist. The patient was referred for hepatitis $C$ treatment using IFN-free DAA, which resulted in the improvement of the symptoms of OLP. This case represents the safety and efficacy of IFN-free DAAs in patients with 


\section{Case Reports in Gastroenterology}

Case Rep Gastroenterol 2016;10:617-622

(c) 2016 The Author(s). Published by S. Karger AG, Basel www.karger.com/crg

Misaka et al.: Use of Direct-Acting Antivirals for the Treatment of Hepatitis C

Virus-Associated Oral Lichen Planus: A Case Report

HCV-associated OLP. However, long-term follow-up studies are required to elucidate the therapeutic effects of this therapy in these patients.

\section{Introduction}

The hepatitis $\mathrm{C}$ virus (HCV) causes various extrahepatic manifestations in the tissues and organs except for the liver [1]. Cryoglobulinemia, membranoproliferative glomerulonephritis, malignant lymphoma, lichen planus (LP), and diabetes are representative diseases of the extrahepatic manifestations of HCV.

LP is an inflammatory lesion that develops in the skin or mucosa. The association between oral LP (OLP) and HCV infection has been reported frequently [2, 3]. The rates of HCV infection in OLP are especially high in Japan and Italy. Thus, a dentist has many opportunities to diagnose patients with OLP in the clinical setting and may discover HCV-infected patient.

Interferon (IFN) treatment has taken a central role in the eradication of HCV until now $[4,5]$. However, the discovery of IFN-free direct-acting antivirals (DAA) with high sustained virological response (SVR) rates and few side effects has changed the treatment of hepatitis C remarkably [6-8]. In July 2014, Japan approved the use of a combination therapy with daclatasvir (DCV; NS5A inhibitor) and asunaprevir (ASV; NS3 protease inhibitor), making it the first approved, all-oral, IFN/ribavirin-free DAAs therapy.

We have previously reported the first successful use of IFN-free DAAs in patients with HCV-associated OLP [9]. Herein, we report the case of a 60-year-old female who was diagnosed with OLP by a dentist and subsequently treated for HCV using DAA.

\section{Case Presentation}

In April 2013, a 60-year-old Japanese female visited the Misaka dental clinic (Fukuoka, Japan) complaining of gingival discomfort and was diagnosed with periodontitis. During treatment, the dentist and the dental hygienist noticed several white spots on the gingiva (fig. 1a). Characteristic white papules were observed on the upper and lower gingivae as well as the buccal mucosae, bilaterally. The lesions were clinically diagnosed as OLP by a specialist oral surgeon. Regular treatment for the periodontal disease reduced the gingival bleeding and swelling; however, the white spots on the gingiva and buccal mucosae did not disappear.

The patient was not aware of any HCV infection until she received the examination when she was admitted to a hospital for the treatment of a uterine myoma at the age of 40 (in 1993). There was no history of blood transfusion, tattoo, or injection drug use. Moreover, the patient was not a habitual alcohol drinker or smoker. She subsequently received IFN alpha-2b therapy for chronic HCV thrice weekly for half a year, followed by retreatment 1 year later. However, the IFN therapy was stopped because of the side effect of malaise and thus did not reach SVR. Thereafter, she was treated with oral ursodeoxycholic acid from 1995 to 2011 in order to improve the liver function. At the age of 59 (in 2012), she received 


\section{Case Reports in \\ Gastroenterology}

Case Rep Gastroenterol 2016;10:617-622

(c) 2016 The Author(s). Published by S. Karger AG, Basel www.karger.com/crg

Misaka et al.: Use of Direct-Acting Antivirals for the Treatment of Hepatitis C

Virus-Associated Oral Lichen Planus: A Case Report

continuous treatment with ursodeoxycholic acid and underwent regular blood tests at the general surgery clinic. She did not receive any new basic therapy for the eradication of HCV and was unaware of the introduction of a new IFN-free DAA in Japan.

During the course of the periodontal treatment at the Misaka Dental Clinic, the patient was educated to the fact that OLP is an extrahepatic manifestation of HCV infection and was also made aware that IFN-free DAA treatment, which is the standard therapy for chronic HCV, was now available in Japan.

On March 4, 2015, the patient was referred to a medical institution. Table 1 shows the results of the clinical examinations. She received DAA treatment involving a 24-week course of DCV (60 mg once daily) and ASV (100 mg twice daily) from May 13, 2015, until October 28,2015 . The eradication of HCV was successful for the treatment of chronic HCV in the patient. The OLP lesion was not aggravated during the DAA therapy. The patient did not receive any medications for OLP. After DAA therapy (SVR24), the gingival and buccal mucosal discomfort had disappeared, along with a significant reduction in the number of white spots. The oral findings at SVR35 are shown in below (fig. 1b).

\section{Discussion}

This case report demonstrates that the diagnosis of OLP followed by the provision of treatment advice by the dentist regarding HCV led to the successful eradication of HCV. Thus, patients with $\mathrm{HCV}$-associated OLP can be safely and effectively treated with IFN-free DAA therapy.

In our previous studies, we analyzed the factors that interfere with the acceptance of IFN therapy in HCV-infected patients $[10,11]$. Multivariate analysis showed that the factors contributing to the risk that a patient might not consent to receiving IFN therapy include treatment facilities (hepatologist/nonhepatologist), sex (female/male), and the occurrence of complications (yes/no) [11]. The adjusted odds ratios for these 3 factors were 18.06, 3.65, and 3.63, respectively. The most common reasons for declining IFN therapy was 'worries over adverse reactions'.

In Japan, IFN-free DAA was released in 2014, but unfortunately, sufficient information about the standard therapy was not provided; neither to the patients with HCV nor to nonhepatologists. The patient in this case study had a negative impression due to the side effects associated with IFN therapy. Furthermore, lack of awareness regarding the availability of the new DAA treatment prevented her from receiving additional treatment for more than 20 years. Hence, discovery of the onset of OLP in the dental clinic enabled the dentist to provide the patient with information about the extrahepatic manifestations of HCV and the latest treatment available.

HCV-infected patients presenting with extrahepatic manifestations generally consult physicians from various departments including dentistry, dermatology, blood internal medicine, and renal internal medicine. Advance and adequate knowledge regarding the extrahepatic manifestation of this disease may help patients with HCV in receiving treatment in a timely and efficient manner.

Previously, we had reported the outcomes of HCV-associated OLP in 7 patients who received successful treatment with IFN-free DAAs using the DCV/ASV combination therapy [9]. 
The OLP lesions had disappeared in 4 and improved in 3 out of the 7 patients after SVR24. The symptoms of OLP had subsided in all patients. The symptoms of HCV-associated OLP are often exacerbated following IFN therapy [12-14]; therefore, IFN-free DAA therapy appears to be a safer and more effective approach for the treatment of OLP.

In conclusion, the patient with HCV-associated OLP in the present case study was treated using IFN-free DAA, which led to improvement in the symptoms of OLP. Long-term follow-up studies are needed to elucidate the therapeutic effects of this therapy.

\section{Acknowledgements}

We thank Dr. Keiichi Ariyoshi and Onga Nakama Dental Association for cooperation of clinical case conference about liver disease. Clinical case conference was supported in part by a Grant-in-Aid for Scientific Research (C) (No. 25463274) from the Ministry of Education, Culture, Sports, Science and Technology of Japan.

\section{Statement of Ethics}

The authors have no ethical conflicts to disclose. Informed consent was obtained from the patient for being included in the report.

\section{Disclosure Statement}

Y.N. and Y.K. belong to a department funded by Nishinihon Hospital. K.M., T.K., and M.S. declare no conflicts of interest.

\section{References}

1 Gumber SC, Chopra S: Hepatitis C: a multifaceted disease. Review of extrahepatic manifestations. Ann Intern Med 1995;123:615-620.

2 Nagao Y, Sata M, Tanikawa K, Itoh K, Kameyama T: Lichen planus and hepatitis C virus in the northern Kyushu region of Japan. Eur J Clin Invest 1995;25:910-914.

-3 Lodi G, Pellicano R, Carrozzo M: Hepatitis C virus infection and lichen planus: a systematic review with meta-analysis. Oral Dis 2010;16:601-612.

4 Manns MP, McHutchison JG, Gordon SC, Rustgi VK, Shiffman M, Reindollar R, Goodman ZD, et al: Peginterferon alfa-2b plus ribavirin compared with interferon alfa-2b plus ribavirin for initial treatment of chronic hepatitis C: a randomised trial. Lancet 2001;358:958-965.

5 Fried MW, Shiffman ML, Reddy KR, Smith C, Marinos G, Goncales FL Jr, Haussinger D, et al: Peginterferon alfa-2a plus ribavirin for chronic hepatitis C virus infection. N Engl J Med 2002; 347:975-982.

6 Kumada H, Suzuki Y, Ikeda K, Toyota J, Karino Y, Chayama K, Kawakami Y, et al: Daclatasvir plus asunaprevir for chronic HCV genotype 1b infection. Hepatology 2014;59:2083-2091.

7 Omata M, Nishiguchi S, Ueno Y, Mochizuki H, Izumi N, Ikeda F, Toyoda H, et al: Sofosbuvir plus ribavirin in Japanese patients with chronic genotype 2 HCV infection: an open-label, phase 3 trial. J Viral Hepat 2014;21:762-768. 


\section{Case Reports in Gastroenterology}

Misaka et al.: Use of Direct-Acting Antivirals for the Treatment of Hepatitis C

Virus-Associated Oral Lichen Planus: A Case Report

8 Mizokami M, Yokosuka O, Takehara T, Sakamoto N, Korenaga M, Mochizuki H, Nakane K, et al: Ledipasvir and sofosbuvir fixed-dose combination with and without ribavirin for 12 weeks in treatment-naive and previously treated Japanese patients with genotype 1 hepatitis C: an open-label, randomised, phase 3 trial. Lancet Infect Dis 2015;15:645-653.

-9 Nagao Y, Kimura K, Kawahigashi Y, Sata M: Successful treatment of hepatitis C virus-associated ora lichen planus by interferon-free therapy with direct-acting antivirals. Clin Transl Gastroenterol 2016;7:e179.

10 Nagao Y, Sata M, Suzuki Y, Nobayashi H, Kawakami Y: Toward more widespread use of novel drug therapies: current status of interferon therapy in patients with hepatitis $\mathrm{C}$ and discussion of strategies to propagate its use. Office of Pharmaceutical Industry Research (in Japanese). Res Paper Series 2006;32:1-81.

11 Nagao Y, Kawakami Y, Yoshiyama T, Sata M. Analysis of factors interfering with the acceptance of interferon therapy by HCV-infected patients. Med Sci Monit 2008;14:Pi45-Pi52.

-12 Nagao Y, Sata M, Ide T, Suzuki H, Tanikawa K, Itoh K, Kameyama T: Development and exacerbation of oral lichen planus during and after interferon therapy for hepatitis C. Eur J Clin Invest 1996;26: 1171-1174.

13 Nagao Y, Kawaguchi T, Ide T, Kumashiro R, Sata M: Exacerbation of oral erosive lichen planus by combination of interferon and ribavirin therapy for chronic hepatitis C. Int J Mol Med 2005;15: 237-241.

14 Grossmann Sde M, Teixeira R, de Aguiar MC, do Carmo MA: Exacerbation of oral lichen planus lesions during treatment of chronic hepatitis $\mathrm{C}$ with pegylated interferon and ribavirin. Eur J Gastroenterol Hepatol 2008;20:702-706.
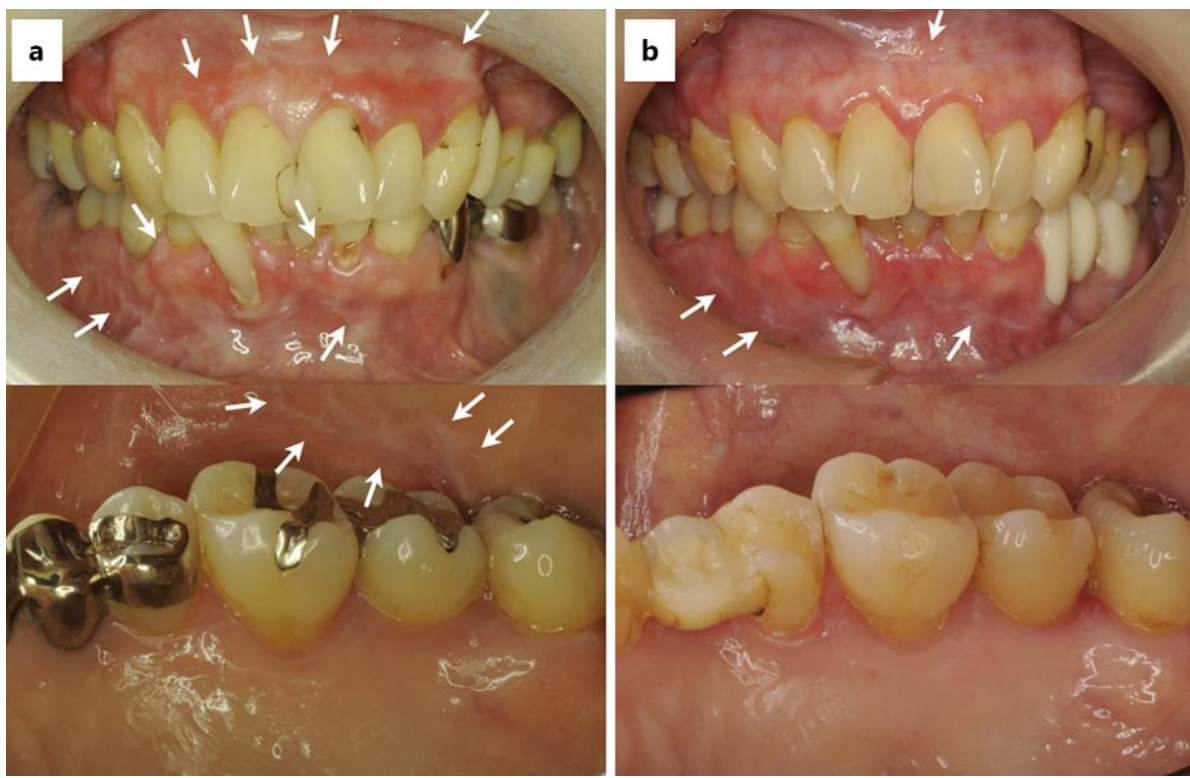

Fig. 1. a Upper panel: OLP lesions observed on the upper and lower gingivae in the 60-year-old female during her first visit to the clinic (April 2013) (arrows). Lower panel: the OLP lesion was also present on the buccal mucosa, bilaterally (April 2013). b Upper panel: the white spots of OLP became faint and appeared to reduce by SVR35 (June 2016). Lower panel: disappearance of OLP on the buccal mucosa (June 2016). The white arrows show the OLP lesions. 
Table 1. Comparison of the laboratory data at baseline and SVR24

\begin{tabular}{|c|c|c|c|}
\hline & Normal range & $\begin{array}{l}\text { Baseline, } \\
\text { March 4, } 2015\end{array}$ & $\begin{array}{l}\text { SVR24, } \\
\text { April 13, } 2016\end{array}$ \\
\hline HCV genotype & not detected & $1 b$ & \\
\hline $\begin{array}{l}\text { Level of HCV RNA, } \\
\log \mathrm{IU} / \mathrm{ml}\end{array}$ & not detected & 6.3 & \\
\hline Anti-HCV & negative & positive & \\
\hline Anti-HBc & negative & positive & \\
\hline HBsAg & negative & negative & \\
\hline $\begin{array}{l}\text { Existence of DCV- } \\
\text { resistant NS5A-L31M }\end{array}$ & not detected & wild type & \\
\hline $\begin{array}{l}\text { Existence of DCV- } \\
\text { resistant NS5A-Y93 }\end{array}$ & not detected & wild type & \\
\hline AST, U/I & 13-33 & 37 & 23 \\
\hline ALT, U/I & $6-27$ & 25 & 12 \\
\hline ALP, U/l & $119-229$ & 251 & 260 \\
\hline Gamma GTP, U/l & $10-47$ & 18 & 13 \\
\hline T.Bil, mg/dl & $0.2-1.5$ & 0.6 & 0.7 \\
\hline D.Bil, mg/dl & $0.1-0.4$ & 0.2 & 0.2 \\
\hline T.pro, g/dl & $6.7-8.3$ & 8.1 & 7.7 \\
\hline $\mathrm{Alb}, \mathrm{g} / \mathrm{dl}$ & $4.0-5.0$ & 4.4 & 4.1 \\
\hline T.cho, mg/dl & $128-256$ & 233 & 252 \\
\hline BUN, mg/dl & $8-22$ & 13 & 14 \\
\hline Crea, mg/dl & $0.4-0.7$ & 0.55 & 0.61 \\
\hline $\mathrm{Na}, \mathrm{nmol} / \mathrm{l}$ & $138-146$ & 140 & 139 \\
\hline $\mathrm{K}, \mathrm{nmol} / \mathrm{l}$ & $3.6-4.9$ & 4.0 & 4.3 \\
\hline $\mathrm{Cl}, \mathrm{nmol} / \mathrm{l}$ & 99-109 & 103 & 103 \\
\hline AFP, ng/ml & $\leq 10.0$ & 3.2 & 2.2 \\
\hline PIVKAII, mAU/ml & $0-28$ & 21 & 28 \\
\hline $\mathrm{RBC}, \times 104 / \mu \mathrm{l}$ & $375-514$ & 464 & 443 \\
\hline $\mathrm{Hb}, \mathrm{g} / \mathrm{dl}$ & $10.6-15.4$ & 14.4 & 13.6 \\
\hline WBC, $\mu \mathrm{l}$ & $3,500-9,500$ & 3,400 & 4,700 \\
\hline $\mathrm{Plt}, \times 104 / \mu \mathrm{l}$ & $16.4-37.6$ & 21.4 & 20.9 \\
\hline HbA1c, \% & $4.6-6.2$ & 5.6 & 5.6 \\
\hline
\end{tabular}

SVR = Sustained virological response; Anti-HCV = anti-HCV antibody; Anti$\mathrm{HBc}=$ anti-hepatitis B core antibody; $\mathrm{HBsAg}=$ hepatitis B surface antigen; AST = aspartate aminotransferase ALT = alanine aminotransferase M; ALP = serum alanine aminotransferase; gamma GTP = gamma glutamyl transpeptidase; T.Bil = total bilirubin; D.Bil = direct bilirubin; T.pro = total protein; Alb = albumin; T.cho = total cholesterol; BUN = blood urea nitrogen; Crea = creatinine; $\mathrm{Na}=$ sodium; $\mathrm{K}=$ potassium; $\mathrm{Cl}$ = chloride; $\mathrm{AFP}=$ alpha fetoprotein; PIVKAII = protein induced by vitamin $\mathrm{K}$ absence or antagonists-II; RBC = red blood cell; $\mathrm{Hb}=$ hemoglobin; $\mathrm{WBC}=$ white blood cell; $\mathrm{PLT}=$ platelets; $\mathrm{HbA1} \mathrm{c}=$ hemoglobin A1c. 